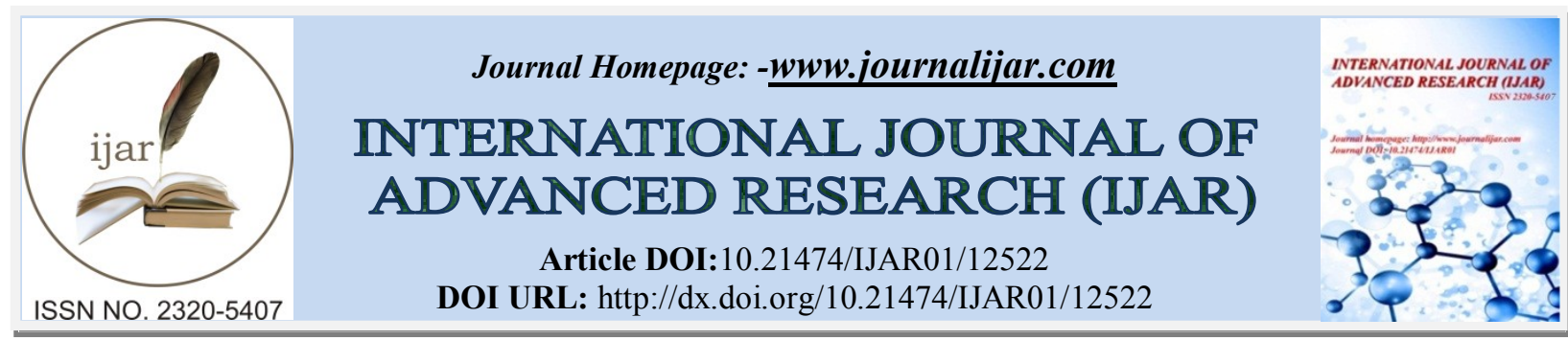

RESEARCH ARTICLE

\title{
ALKALINE LYSIS AS AN EFFICIENT AND ECONOMICAL ALTERNATIVE FOR DNA EXTRACTION FROM HORSEHAIR HAIR SAMPLES: COMPARISON BETWEEN DIFFERENT METHODS
}

\author{
Myriam Janeth Ortega Torres ${ }^{1}$, Jessica Almeida Braga ${ }^{1}$, Camilo Torres ${ }^{1}$ and Ahmed Sami Shaker ${ }^{2}$ \\ 1. School of Agricultural, Livestock and Environmental Sciences - Bogotá, Colombia. \\ 2. Animal Production Department, Directorate of Agriculture Research- Sulaimani, Iraq
}

\section{Manuscript Info}

Manuscript History

Received: 23 December 2020

Final Accepted: 25 January 2021

Published: February 2021

Key words:-

DNA Extraction, Arauca Creole Horses, Sequencing, Mitochondrial DNA

\section{Abstract}

Studies related to DNA extraction are becoming more ambitious in the sense that large studies are intended to be carried out with minimum DNA sources. The DNA extracted must be of quality for genetic, forensic, population and genomic studies, these samples must be easy to obtain and product of efficient manipulation.Samples obtained from horsehair are an important technical challenge since they constitute the preferred non-invasive sample for genetic studies in horses, which has been shown to obtain reliable results in a short time. In this sense, working into effective techniques to optimizeDNA extraction of scarse samples is a pertinent task. In this study, different DNA extraction methods were evaluated from mane samples obtained from a population of wild horses from the Region of Arauca in eastern Colombia.Three DNA extraction methods were evaluated (phenol chloroform, alkaline lysis and twocommercial DNA extraction kit), DNA concentration, purity and qualityweredeterminate and PCR amplification product were obtain using primers for a hypervariable region of DNA mitochondrial. DNA preparation from hair roots using alkaline lysis was the most economical and efficient method with which it was possible to obtain high quality and quantity DNA.

Copy Right, IJAR, 2021,. All rights reserved.

\section{Introduction:-}

Development of different molecular biology techniques, applied to the study of animal populations, has allowed obtaining relevant information for conservation programs (Mai et al., 2020; Rubinoff et al., 2020; Solis et. 2015), inferring phylogenetic relationships and performing biogeographic studies (Bruford et al, 2003; Orlando et al. 2013), genotyping of individuals in forensic genetics, identification of genetic and infectious pathologies, kinship analysis, and identification of QTLs used in animal breeding programs (Schröder, 2012). These analyzes require DNA of good quality and enough quantity to further analysis.

Genetic studies of animal populations require a significant number of samples from different origins, some of them,such as blood samples, can be obtained in high quantity; however, collecting them and keeping maintenance and transport conditions can represent a major challenge for research. Current molecular biology practices have developed different methods that allow obtaining sample DNA from multiple sources (Dixon et al., 2006). It is common to use unconventional samplesin research studies of genetic diversity and wildlife conservation, such as 
feces, hair, skin, bone, as well as tissue segments collected from museum specimens (Moraes-barros\&Morgante, 2007).

To perform genetic diversity analysis, it is necessary to select a series of high polymorphism molecular markers such as microsatellites or SNPs, to evaluate different diversity measures. Obtain quality DNA molecules that will then be amplified using PCR and subsequently typified by any sequencing methods is a big challenger. Many studies need high number of individuals and access to wild species habitats could be difficult and costing. Thus, it is necessary to usehigh efficiency protocols forsampling, preservation and DNA extraction.Extraction protocols must be easy to carry out, reproducible, fast, andmust generate contamination-free products(Veloso et al., 2000).To choose the best extraction protocol, the balance between cost and benefits must be taken into account for the research itself, as well as the low risks to human and animal health and the environment.

Mammal hair samples have been used because they are easy to obtain, transport and preserve. In horses, these samples are easily obtained from the mane or tail of the animal, without it undergoing invasive procedures or requiring the immobilization of the animal. The hair of an animal can be found in two phases, those that are growing (anagen phase) and those that are in a resting state or telogen phase (Ząbek et al., 2018), for extraction and amplification purposes those hairs that contain the hair follicle and the envelopeare preferred, especially when microsatellites or other nuclear markers are amplified.

This work compares three DNA extraction methods (Phenol-Chloroform, Commercial Kit and Alkaline Lysis) obtained from horsehair samples of creole horses from the eastern region of Colombia (Arauca) and their efficiency to amplify and sequence a fragment of the D-loop region of horse mitochondrial DNA (mitDNAD-loop), with the aim of looking for differences in yield of DNA quality according to the usedprotocol.

\section{Materials andMethods: -}

\section{Hair sampling}

Collection of hair samples from the creole horse was carried out at "Finca el Desastre" in the city of Arauca, in eastern Colombia. The consent of the specimen owners was obtained, and the animal welfare conditions were kept in mind. After tying each of the specimens, a sample of approximately 200 hairs was taken from the mane, which were plucked, wrapped in paper and kept away from light and moisture, all hairs includedfollicle.

\section{DNA Extraction}

For DNA extraction, two pre-established and modified DNA extraction methods were used, and 2 protocols of commercial kits were tested, one from Qiagen and the other from Promega according to instructions from commercial companies, therefore, four different protocols were carried out as well: 1-Phenol-Chloroform Protocol, 2- Qiagen Commercial Kit, 3-Alkaline Lysis Protocol,and 4-Promega Commercial Kit. For each of these procedures, horsehair segments of approximately $0.5 \mathrm{~cm}$ in length were used and 5 and 10 hairs with follicle and without follicle were taken, except for the extraction protocol of the Promega commercial kit, where 5 and 10 hairs with follicle were used. Prior to any of these treatments, the hair fragments were washed with distilled water.

\section{Phenol-chloroform extraction (Protocol A)}

The samples of 5 and 10 hairs with and without follicles were left to digest in a water bath at $56^{\circ} \mathrm{C}\left(132.8^{\circ} \mathrm{F}\right)$ overnight, in a solution of $500 \mu \mathrm{l}$ lysis buffer (Sodium Chloride-Tris-EDTA (pH 8), $20 \mu 1$ of proteinase K and $10 \mu 1$ of DTT, after incubation, this material was mixed with a solution of phenol-chloroform, isoamyl alcohol (25: 24: 1) and was centrifuged for 10 minutes. The aqueous phase was recovered by adding a mixture of chloroform-isoamyl alcohol (24: 1) and centrifuged again for 10 minutes, after which the aqueous phase was recovered and $30 \mu l$ of ammonium acetate and $750 \mu \mathrm{l}$ of $100 \%$ ethanol were added, the material remained at $-20^{\circ} \mathrm{C}\left(-4^{\circ} \mathrm{F}\right)$ for two hours. Subsequently, two washes were carried out with $300 \mu \mathrm{l}$ of $70 \%$ ethanol (Sambrook et al., 1989), and finally the pellet was resuspended in $30 \mu \mathrm{l}$ of ultrapure water.

\section{Extraction with Qiagen Commercial Kit (Protocol B)}

QIAamp DNA Investigator Kit protocol was carried out according to instructions given by the commercial company. 


\section{Extraction with alkaline lysis (Protocol C)}

The protocol used was the one described byBirnboim and Doly (1979), modified in our laboratory to eukaryotic cell. Horsehair segments were cut, closest to the root and placed in $0.5 \mathrm{ml}$ Eppendorf tubes, $100 \mu \mathrm{l}$ of solution A (200mM $\mathrm{NaOH}$ ) was added, heated in a THERM 1000 thermocycler (AxygenMaxygene $\left.{ }^{\mathrm{TM}}\right)$ for 15 minutes at $97^{\circ} \mathrm{C}\left(206.6^{\circ} \mathrm{F}\right)$, after this time $100 \mu \mathrm{l}$ of solution $\mathrm{B}(200 \mathrm{mM} \mathrm{HCl}+100 \mathrm{mM}$ TRIS HCl, $\mathrm{pH} 8.5)$ were added, shaking the mixture that was then stored at $-20^{\circ} \mathrm{C}\left(-4^{\circ} \mathrm{F}\right)$, until its use for PCR.

\section{Extractionwithcommercial Promega kit (Protocol D)}

ExtractionunderWizard ${ }^{\circledR}$

Genomic

DNA

Purificationkitprotocolwascarriedoutaccordingtoinstructionsgivenbythecommercialcompany.

\section{DNA quantification}

I. DNA concentrationwasdeterminedbyspectrophotometry, at thesame time theabsorbance of ultraviolet light at $260 \mathrm{~nm}$ for DNA and 280 forproteinsweremeasured, thepurity of theextracted DNA wasdeterminedbythe ratio between OD 260 / OD 280, in a Nanodropequipment 2000 fromThermoScientific ${ }^{\mathrm{TM}}$.A ratio greaterthan 1.7 indicatescontamination of theextractionwithproteins.

II. Amplification of D-loopregion of mitochondrial DNA

After DNA extraction process, DNA from the protocolthat delivered the best results was used to carry out the PCR amplification of a mitochondrial DNA segment, located within the D loop region inhorse mitochondria, using the pair of 5'CCACCATCAACACCCAAAGC-3'and R 5'-GCCCTGAAGAAAGAACCAGAT3' primers according to Jiménez et al (2012), 35 amplification cycles were performed in an Eppendorf Vapo.ProtectThermal Cycler, with an initial temperature of $95^{\circ} \mathrm{C}\left(203^{\circ} \mathrm{F}\right)$ for two minutes, denaturation for 10 seconds at $94^{\circ} \mathrm{C}\left(201.2^{\circ} \mathrm{F}\right)$, annealing at $57^{\circ} \mathrm{C}\left(134.6^{\circ} \mathrm{F}\right)$ for one minute and extension temperature $68^{\circ} \mathrm{C}$ for one minutes $\left(154.4^{\circ} \mathrm{F}\right), 5 \mu 1$ of DNA was used, for a total reaction volume of $20 \mu$. This amplification was carried out to confirm the origin of the extracted DNA.

III. After PCR, themitochondrial DNA fragmentsobtainedwerevisualized in $2 \%$ agarosegels.

IV. Sequencing

V. The PCR productsampleswerepurifiedaccordingtothepurificationprotocolestablishedbytheBioMol

Laboratory of theNationalUniversity of Colombia, which in summaryconsists of carryingouttwowashes of the PCR product, withammoniumacetate and coldethanol, and thenothertwowasheswith pure ethanol. Once thispurificationprocedurewasperformed, thesamplesweresequenced on anAppliedBiosystems ${ }^{\mathrm{TM}} 3500$ analyzer.Thesesequenceswerevisualized in BioEditSoftwareProgram (Hall, 1999) and multiplealignmentswereperformedusingBLAST(Altschul, 1990) againstsequencesstored in theGenBankDatabase.

\section{Statistical analysis}

Data was analyzed from a randomized block design, since the existence of possible effects from the DNA extraction methods (treatments) was evaluated and these are applied to groups of hairs with and without follicles (blocks). The following model was used:

Where:

$$
\mathrm{Y}_{\mathrm{ij}}=\mu+\tau_{\mathrm{i}}+\beta_{\mathrm{j}}+\varepsilon_{\mathrm{ij}}
$$

$\mathrm{i}=$ Phenol, Qiagen, Alkaline Lysis (LysisA), Promega (Prom)

$\mathrm{j}=$ With follicle (WF), Without follicle (noF)

VI. Data wasanalyzedwithRStudio software program (2020).

\section{Results:-}

Results show that it was possible to obtain DNA from both horsehair hair with a follicle and without a follicle, within these two blocks, no significant differences were found, regarding the amount of DNA extracted after using four different extraction protocols (Table 1).

Table 1:- Result of the analysis of varianceof hair extraction methods from Creole horse mane, with or without follicle (blocks).

\begin{tabular}{|l|l|l|}
\hline Variationsources & Nanograms / Milliliters & Absorbance260/280 \\
\hline F Method & 0.055 & 0.432 \\
\hline
\end{tabular}




\begin{tabular}{|c|c|c|}
\hline F Blocks & 0.674 & 0.377 \\
\hline CV & 105,52 & 82,237 \\
\hline
\end{tabular}

The DNA extraction protocol using alkaline lysis showed the best performance for horsehair DNA extraction, with an average of 49 nanograms per microliter, followed by the Qiagen and Phenol Chloroform protocols, the one that showed the lowest yield was the protocol using the commercial kit from Promega. Regarding DNA quality, determined by the absorbance ratio at $260 \mathrm{~nm} / 280 \mathrm{~nm}$, the methods with best results were those using the two commercial kits for extraction (Table 2).

Table 2:- Comparison of four DNA extraction protocols.

\begin{tabular}{|l|ll|lc|}
\hline METHODS & \multicolumn{2}{|l|}{ Nanograms / Milliliters } & \multicolumn{2}{|l|}{ Absorbance 260/280 } \\
\hline Fenol & $2,075 \mathrm{~b}$ & $( \pm 3,656)$ & $4,00 \mathrm{a}$ & $( \pm 3,061)$ \\
\hline Qiagen & $22,40 \mathrm{ab}$ & $( \pm 23,932)$ & $2,157 \mathrm{a}$ & $( \pm 2,000)$ \\
\hline AlkalineLysis & $49,433 \mathrm{a}$ & $( \pm 28,976)$ & $4,106 \mathrm{a}$ & $( \pm 2,676)$ \\
\hline Promega & $-2,70 \mathrm{~b}( \pm 0,5656)$ & $0,960 \mathrm{a}$ & $( \pm 0,071)$ \\
\hline
\end{tabular}

A total of 100 samples of horsehair were amplified using the Alkaline Lysis protocol, an amplification percentage of $60 \%$ was obtained, where the band corresponding to the amplification product of 364 base pairs of the mtDNADloop region of the horse breed was observed (figure 1).

\section{$\begin{array}{lllllllllllllllllll}M P & 1 & 2 & 3 & 4 & 5 & 6 & 7 & 8 & 9 & 10 & 11 & 12 & 13 & 14 & 15 & 16 & 17 & 18\end{array}$}

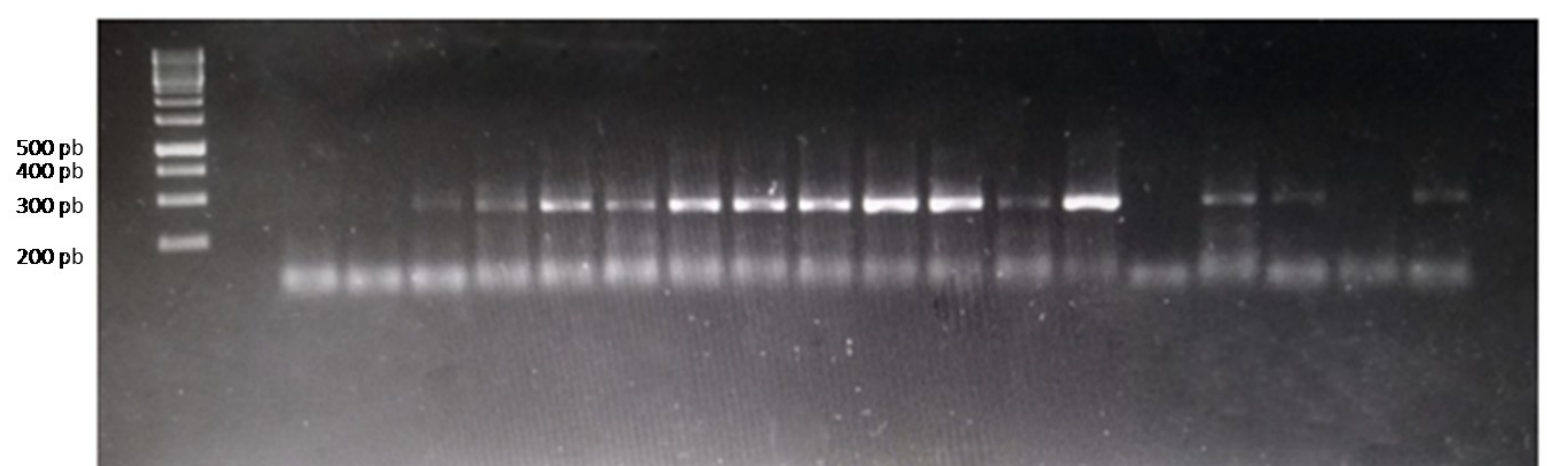

Figure 1:- Amplification of mitochondrial DNA segment using DNA extracted from horse mane, on the left the molecular weight marker $(1 \mathrm{~Kb})$ is observed, on the right 18 DNA samples can be observed, with successful amplification in 14 of them. Samples 1, 2, 14 and 17, did not amplify.

The results of thehorsehair samples sequencing, whose DNA was obtained using the alkaline lysis extraction protocol, showed a high-quality sequence, as seen in the electropherogram (figure 2), the peaks for each of the bases are high and well differentiated allowing the total reading of the sequence (figure 2).

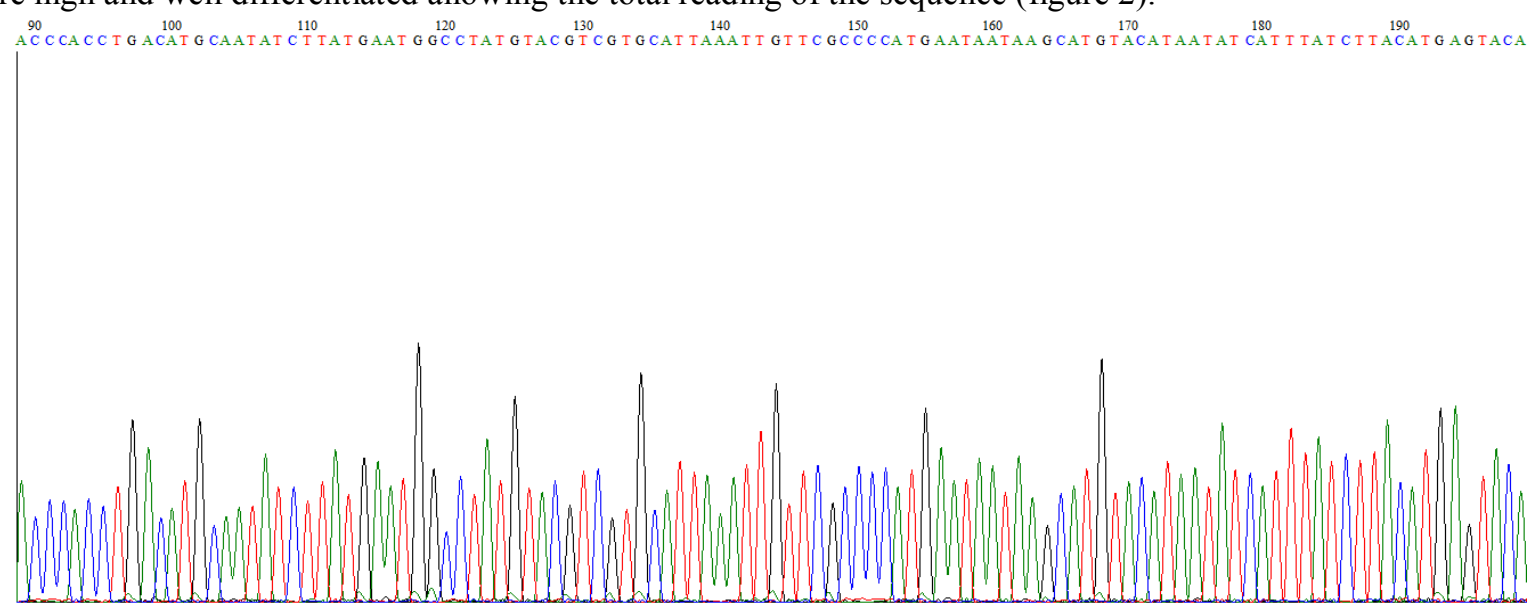


Figure 2:- Amplified DNA sequence for mitochondrial D-Loop segment from DNA extracted with alkaline lysis extraction protocol.

When the sequences are contrasted against the GenBank Database (https:/www.ncbi.nlm.nih.gov/genbank/), performing a BLASTAnalysis, a percentage of 100\% identity is obtained with the MG761996 locus that corresponds to the mitochondrial DNA sequence of Equus Caballus (Figure 3).

\begin{tabular}{|c|c|c|c|c|c|c|}
\hline \multicolumn{2}{|c|}{$\begin{array}{l}\text { Score } \\
745 \text { bits(403) }\end{array}$} & $\begin{array}{l}\text { Expect } \\
0.0\end{array}$ & $\begin{array}{l}\text { Identities } \\
403 / 403(100 \%)\end{array}$ & $\begin{array}{l}\text { Gaps } \\
0 / 403(0 \%)\end{array}$ & $\begin{array}{l}\text { Strand } \\
\text { Plus/Plus }\end{array}$ & \\
\hline uery & 6 & \multirow{2}{*}{\multicolumn{4}{|c|}{ 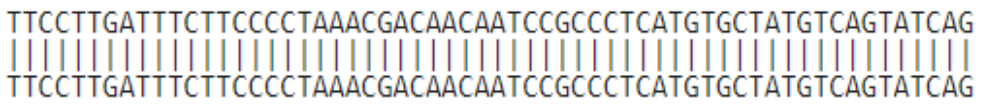 }} & 65 \\
\hline bjct & 15459 & & & & & \\
\hline dery & 66 & \multirow{2}{*}{\multicolumn{4}{|c|}{$\begin{array}{l}\text { ATTATACCCCCATATAACACCATACCCACCTGACATGCAATATCTTATGAATGGCCTATG } \\
\text { || |||||||||||||||||||||||||||||||||||||||||||||||||||||||||||||||||| } \\
\text { ATTATACCCCCATATAACACCATACCCACCTGACATGCAATATCTTATGAATGGCTATG }\end{array}$}} & \\
\hline jct & 9 & & & & & \\
\hline jery & 126 & \multirow{2}{*}{\multicolumn{4}{|c|}{ 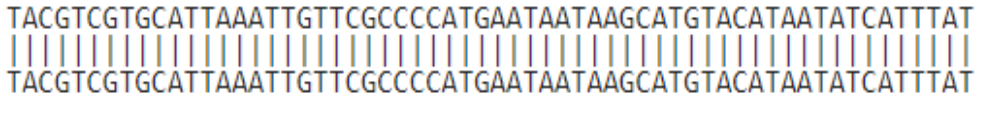 }} & 18 \\
\hline bjct & 15579 & & & & & \\
\hline ery & 186 & \multirow{2}{*}{\multicolumn{4}{|c|}{$\begin{array}{l}\text { CTTACATGAGTACATTATATTATTGATCGTGCATACCCCATCCAAGTCAAATCATTTCCA } \\
\text { |||||||||||||||||||||||||||||||||||||||||||||||||||||||||||||||||| } \\
\text { CTTACATGAGTACATTATATTATTGATCGTGCATACCCCATCCAAGTCAAATCATTTCCA }\end{array}$}} & 245 \\
\hline jct & 15 & & & & & 15 \\
\hline Query & 246 & \multirow{2}{*}{\multicolumn{4}{|c|}{$\begin{array}{l}\text { GTCAACACGCATATCACAACCCATGTTCCACGAGCTTAATCACCAAGCCGCGGGAATCA } \\
|||||||||||||||||||||||||||||||||||||||||||||||||||||||| \mid \\
\text { GTCAACACGCATATCACAACCCATGTTCCACGAGCTTAATCACCAAGCCGCGGGAATCA }\end{array}$}} & 305 \\
\hline jct & 1 & & & & & 1 \\
\hline dery & 306 & \multirow{2}{*}{\multicolumn{4}{|c|}{$\begin{array}{l}\text { GCAACCCTCTCAACTACGTGTCCCAATCCTCGCTCCGGGCCCATCCAAACGTGGGGGTT } \\
\text { || |||||||||||||||||||||||||||||||||||||||||||||||||||||||||||||| } \\
\text { GCAACCCTCTCAACTACGTGTCCCAATCCTCGCTCCGGCCCATCCAAACGTGGGGTT }\end{array}$}} & 365 \\
\hline bjot & 15759 & & & & & 1581 \\
\hline Query & 366 & \multirow{2}{*}{\multicolumn{3}{|c|}{$\begin{array}{l}\text { CTACAGTGAACTATACCTGGCATCTGGTTCTTTCTTCAGGGC } \\
\text { |||||||||||||||||||||||||||||||||||||||||||||||| } \\
\text { CTACAGTGAACTATACCTGGCATCTGGTTCTTTCTTCAGGG }\end{array}$}} & & \\
\hline bjct & 15819 & & & & & \\
\hline
\end{tabular}

Figure 3:- Comparison of one of the DNA sequences obtained, using the Alkaline Lysis extraction method, which showed identity with the Equus caballus sequence, reported in the GenBank database.

\section{Discussion:-}

The results of this work showed that it is possible to use non-invasive, fast and easy methods to obtain DNA from horsehair, even without a follicle, or in the Telogen Phase characterized by decreased follicle growth and root death. Obtaining DNA from hair in the Telogen Phase has been controversial and constitutes an important field for forensic genetics, authors such as Healy et al. (1995), state that it is not possible to obtain DNA from hair without a follicle, however, the results obtained from this work, as well as that of other authors, such as Higuchi (1988) and Heywood (2003), allow us to suggest that not all DNA is degraded during the hair keratinization process, since it was possible to quantify high molecular weight DNA, after extraction using material in this phase.

The Alkaline Lysis protocol was the method through which the greatest amount of DNA was obtained. It appears that treating hair cells with sodium hydroxide $(\mathrm{NaOH})$ and heat is more than sufficient to achieve cell lysis and release chromosomal and mitochondrial DNA. A subsequent treatment with Tris-HCl Buffer would complete the destabilization of the cell membrane polysaccharides, in addition to stabilizing the $\mathrm{pH}$.This protocol used $\mathrm{NaOHwithout} \mathrm{the} \mathrm{presence} \mathrm{of} \mathrm{the} \mathrm{anionic} \mathrm{detergent} \mathrm{SDS} \mathrm{(Sodium} \mathrm{Dodecyl} \mathrm{Sulfate),} \mathrm{which} \mathrm{commonly} \mathrm{accompanies}$ cell lysis processes, and it was efficient to extract mitochondrial DNA from horsehair, the highest concentrations of DNA from hair with follicle were obtained with this protocol,reaching an average of 49 nanograms per microliter. Using this extraction method, a successful amplification of $60 \%$ was obtained, demonstrating a high sensitivity of the PCR reaction, using DNA extracted from hair as the initial substrate.Efficiency of $60 \%$ may be due to the presence of eumelanin and pheomelanin residues from horse mane hair, which are PCR inhibitors, by forming an inactive complex made up of two molecules of melanin and one of Taq polymerase (Eckhart, L. et al., 2000). 
The Alkaline Lysis method proved that it can be used reliably to extract DNA from horsehair samples, when sequencing is to be performed, this was evidenced by the high success in obtaining clean sequences, with electropherograms showing clear and high peaks that allow the sequence to be correctly read, which was confirmed by a search with BLAST in GenBank and whose result obtained the horse mitochondrial DNA sequence, located within the D-loop region and delimited by the specificity of the primers used for the PCR reaction.

The other extraction protocols showed a lower amount of DNA than that obtained by the Alkaline Lysis method, and they were not used in the amplification and sequencing analyzes. The low concentration of DNA obtained from the extraction with the kits from the two commercial companies may be due to the fact that they are not specific kits for hair or that few hairs were used in the extraction.

\section{Conclusion:-}

The standardization of the horsehair DNA extraction protocol using the Alkaline Lysis protocol offers an easy, fast and economical method for obtaining DNA that will be used for Population Genetic Studies. With this method, it was possible to use non-invasive sampling to obtain high-quality DNA, proven by the results of PCR, sequencing and bioinformatics search, to perform analysis of a significant number of animals, using markers on the mitochondrial DNA molecule.

\section{References:-}

1. Dixon, L. a, Dobbins, a E., Pulker, H. K., Butler, J. M., Vallone, P. M., Coble, M. Parson,

2. W., Berger, B., Grubwieser, P., Mogensen, H. S., Morling, N., Nielsen, K., Sanchez, J. J., Petkovski, E., Carracedo, a, Sanchez-Diz, P., Ramos-Luis, E., Briōn, M., Irwin, J. and Gill, P. (2006). Analysis of artificially degraded DNA using STRs and SNPs--results of a collaborative European (EDNAP) exercise. Forensic Science International, 164(1), 33-44. https://doi.org/10.1016/j.forsciint.2005.11.011

3. Higuchi, R., von Beroldingen, C., Sensabaugh, G. et al. DNA typing from single

4. hairs. Nature 332, 543-546 (1988). https://doi.org/10.1038/332543a0

5. Birnboim HC \&Doly J (1979) A rapid alkaline extraction procedure for screening recombinant plasmid DNA. Nucl Acids Res 7: 1513-1523

6. Bruford, M., Bradley, D. \&Luikart, G. 2003. DNA markers reveal the complexity of livestock domestication. Nat Rev Genet 4, 900-910 (2003). https://doi.org/10.1038/nrg1203.

7. Eckhart, L. et al. (2000) Melanin binds reversibly to thermostable DNA polymerase and inhibits its activity. Biochem. Biophys. Res. Comm. 271, 726-30.

8. Healy PJ, Dennis JA, Moule JF. Use of hair root as a source of DNA for the detection of heterozygotes for recessive defects in cattle. Aust Vet J. 1995;72(10):392. doi:10.1111/j.1751-0813.1995.tb06178.x

9. Mai N. Miyata, DaisukeKageyama, Masashi Nomura. 2020. Multiplex PCR for identification of two butterfly sister species: Eurema mandarina and Euremahecabe, BMC Research Notes, 10.1186/s13104-020-05093$3,13,1$.

10. Orlando, L., Ginolhac, A., Zhang, G. et al .(2013) Recalibrating Equus evolution using the genome sequence of an early Middle Pleistocene horse. Nature, 499, 74-78.

11. RStudio Team (2020). RStudio: Integrated Development for R. RStudio, PBC, Boston, MA URL http://www.rstudio.com/.

12. Rubinoff Daniel Reil, J. Bradley, Osborne Kendall H, Gregory Christopher J., . Geib Scott M, . Dupuis Julian R. 2020. Phylogenomics reveals conservation challenges and opportunities for cryptic endangered species in a rapidly disappearing desert ecosystem, Biodiversity and Conservation, 10.1007/s10531-020-01968-w.

13. Schröder W, Klostermann A, Stock KF, Distl O. A genome-wide association study for quantitative trait loci of show-jumping in Hanoverian warmblood horses. Anim Genet. 2012;43(4):392-400. doi:10.1111/j.13652052.2011.02265.x

14. Solis A, Jugo B. M., J. C. Iriondo MériauxM. , Mazón L. I., Aguirre A. I., A. Vicario, A. Estomba. 2005. Genetic Diversity Within and Among Four South European Native Horse Breeds Based on Microsatellite DNA Analysis: Implications for Conservation, Journal of Heredity, Volume 96, Issue 6, Pages 670678, https://doi.org/10.1093/jhered/esi123.

15. Ząbek, T., Radko, A., \&Słota, E. (2018). Implications for the use of horse hair roots as

16. DNA source for microsatellite typing. Czech Journal of Animal Science, 50(No. 11), 499

17. 502. https://doi.org/10.17221/4254-cjas. 